\title{
Caracterization of adults with cerebral palsy
}

\author{
Caracterização de adultos com paralisia cerebral
}

\author{
Anna L. M. Margre, Maria G. L. Reis, Rosane L. S. Morais
}

\begin{abstract}
Background: Cerebral Palsy (CP) is a group of permanent disorders of the development of movement and posture that cause functional limitation and are attributed to non-progressive disorders which occur in the fetal or infant brain. In recent years, with the increase in life expectancy of individuals with CP, several studies have described the impact of musculoskeletal disabilities and functional limitations over the life cycle. Objective: To characterize adults with CP through sociodemographic information, classifications, general health, associated conditions, physical complications and locomotion. Methods: Twenty-two adults with CP recruited from local rehabilitation centers in an inner town of Brazil participated in this study. A questionnaire was used to collect data on sociodemographic characteristics, comorbities, and physical complications. A brief physical therapy evaluation was carried out, and the Gross Motor Function Classification System (GMFCS) and the Manual Ability Classification System (MACS) were applied. Data were analyzed through descriptive statistics. Results: The mean age was 28.7 (SD 10.6) years, $86.4 \%$ of participants lived with parents, and $4.5 \%$ were employed. Most of the sample consisted of spastic quadriplegic subjects, corresponding to levels IV and V of the GMFCS and MACS. Different comorbidities and important physical complications such as scoliosis and muscle contractures were present. More than half of the participants were unable to walk. Coclusions: Most participants demonstrated important restrictions in social participation and lower educational level. Adults with CP can be affected by several physical complications and progressive limitations in gait.
\end{abstract}

Key words: cerebral palsy; aging; sociodemographic data; classification; complications; locomotion.

\section{Resumo}

Contextualização: Paralisia Cerebral (PC) é um grupo de perturbações permanentes no desenvolvimento de movimentos e posturas que causam limitação nas atividades funcionais e que são atribuídas a distúrbios não-progressivos que ocorrem no cérebro fetal ou infantil. Nos últimos anos, com o aumento na expectativa de vida dos indivíduos com PC, vários estudos têm descrito a instalação de deficiências musculoesqueléticas e limitações funcionais ao longo do ciclo vital. Objetivo: Caracterizar adultos com PC por meio de informações sociodemográficas, classificações, saúde geral e condições associadas, complicações físicas e locomoção. Métodos: Participaram deste estudo 22 adultos com PC residentes em uma cidade no interior do Brasil, recrutados nos centros de reabilitação locais. Aplicou-se um questionário para caracterização sociodemográfica, de comorbidades e complicações físicas. Além disso, realizou-se breve avaliação fisioterapêutica e aplicaram-se as classificações padronizadas, Sistema de Classificação da Função Motora Grossa (GMFCS) e Sistema de Classificação das Habilidades Manuais (MACS). Os dados foram analisados de forma descritiva. Resultados: A média de idade foi de 28,7 anos, 86,4\% participantes moravam com os pais, 4,5\% possuíam emprego. A maior parte da amostra era composta por quadriplégicos espásticos, níveis IV e V do GMFCS e do MACS. Houve presença de diferentes comorbidades e importantes complicações físicas, como escoliose e contraturas musculares. Mais da metade dos participantes não deambula. Conclusões: A maioria dos participantes demonstrou ter importante restrição na participação social, além de escolaridade baixa. Adultos com PC estão sujeitos ainda a instalação de várias complicações físicas e limitações progressivas na marcha.

Palavras-chave: paralisia cerebral; envelhecimento; dados sociodemográficos; classificação; complicações; locomoção.

Received: 21/06/2009 - Revised: 16/11/2009 - Accepted: 21/12/2009 


\section{Introduction $: \because$.}

Cerebral Palsy (CP) is a "group of permanent disorders of the development of movement and posture that cause limitations in functional activities and are attributed to non-progressive disorders which occur in the fetal or infant brain"1. The natural course of $\mathrm{CP}$ has changed a lot over the past 50 years. For example, studies in several countries have demonstrated that life expectancy of individuals with $\mathrm{CP}$ has increased ${ }^{2-4}$. According to Donkervoort et al. ${ }^{5}$, children with $\mathrm{CP}$ who have no significant comorbidities and receive adequate medical care may have survival similar to that of the general population.

$\mathrm{CP}$ is a permanent condition, and although the neurological lesion is static, its associated musculoskeletal sequels may change throughout life ${ }^{6}$. In recent years, studies have described a gradual onset of sequels such as orthopedic deformities ${ }^{6,7}$, decreased muscle strength and flexibility ${ }^{8,9}$, joint degeneration ${ }^{10}$, osteoporosis ${ }^{11,12}$, fatigue ${ }^{13,14}$ and pain ${ }^{14,15}$. Besides, there are reports of progressive

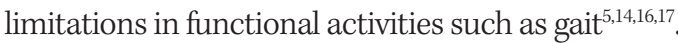

Research on the health-related characteristics of adults with $\mathrm{CP}$ is important to assist healthcare professionals in providing appropriate care, to evaluate the need of targeted public health policies, as well as to contribute to the formulation of adequate preventive strategies for children with $\mathrm{CP}^{16,17}$.

In recent years, there is a growing stream of studies on adults with $\mathrm{CP}^{2,3,13,16,18-22}$, especially in developed countries ${ }^{2,3,13,16,18-20,22}$. It is known that within a biopsychosocial perspective, the physical, social, cultural and political environments can influence the health of adults with $\mathrm{CP}^{23}$. Therefore, it is important to know the needs, living conditions, functional limitations and social restrictions of Brazilian adults with $\mathrm{CP}$.

The aim of this study was to characterize Brazilian adults with CP through socio-demographic information (age, gender, education, marital status, economic level, employment, housing status and family formation), CP classification (neuromotor dysfunction, topographic distribution, gross and fine motor function), general health, associated conditions, physical complications, and mode of locomotion.

\section{Methods $: \because$.}

\section{Study design and participants}

This was a descriptive study to characterize Brazilian adults with CP. Twenty-two adults with $\mathrm{CP}$ recruited from three rehabilitation centers in the city of Diamantina participated in this study. Inclusion criteria were: diagnosis of $\mathrm{CP}$ in the medical records; age 18 years or above; resident of the city of Diamantina. All participants or their guardians signed an informed consent. The study was approved by the Ethics in Research Committee of the Universidade Federal dos Vales do Jequitinhonha e Mucuri (UFVJM), Diamantina (MG), Brazil, protocol 011/09.

\section{Instruments}

To verify the participant's economic level, the Economic Classification Criterion Brazil (Critério de Classificação Econômica Brasil ${ }^{24}$ ) was used. This questionnaire was developed by the Brazilian Association of Research Companies (ABEP), and its score is based on the number of material goods an individual possesses, and their educational level. The general economic classification resulting from the questionnaire ranges from Al (indicating the highest economic class) to $\mathrm{E}$ (indicating the lowest economic class) ${ }^{24}$.

To classify the participant's gross motor function, the Gross Motor Function Classification System (GMFCS) ${ }^{25}$ was applied. The GMFCS is based on voluntary movements, with emphasis on the sitting position and gait. The distinction among the levels of motor function, i.e. I to $\mathrm{V}$, is based on functional limitations and the need for assistive technology ${ }^{25}$. Although the expanded GMFCS includes an age band from 12 to 18 years of age ${ }^{26}$, some studies have used the GMFCS in adults with $\mathrm{CP}^{8,27-29}$.

To classify the fine motor function, the Manual Ability Classification System (MACS) ${ }^{30}$ was used. The MACS is a system that evaluates how children with $\mathrm{CP}$ handle objects in daily activities, and their need for assistance or adjustments ${ }^{30}$. There are five levels of classification, i.e. I to $\mathrm{V}$, with higher levels corresponding to increased limitation in handling objects. According to Haak et al. ${ }^{23}$ and Donnelly et al. ${ }^{29}$, although the MACS has been designed for children, it can also contribute to studies on adults with CP.

A questionnaire addressing several aspects of life in adults with CP has been developed for use in this study (Appendix 1). The questionnaire includes questions on sociodemographic characteristics, classifications, general health, associated conditions, physical complications, and mode of locomotion.

\section{Procedures}

First, medical records of each participant were reviewed to extract information on the type of $\mathrm{CP}$ and its topographic distribution. Then, questionnaires and interviews were completed by the participant. In cases where it was difficult for the participant to express themselves or to understand the questions, the participant's caregiver was asked to answer the questions. If participants reported the presence of associated conditions or physical complications, they were asked to show the results of tests or exams that could confirm that diagnosis.

Inspection and evaluation of passive movements were carried out to verify the presence of deformities, such as 
scoliosis, pelvic obliquity, contractures, or other abnormalities. According to Tardieu ${ }^{33}$, muscle contracture is the loss of muscle extensibility that is observed in the absence of muscle contraction. Because a clinical measure of muscle contracture was used in this study, instead of a measure of electromyographic activity, we acknowledge that neural factors also contributed to an increased resistance to passive movements ${ }^{34}$.

The participant's mode of locomotion was assessed in those who were currently unable to walk by asking if they had been able to walk at some stage in their life. For those who were currently able to walk, the type of walking was assessed according to the "Criteria for Functional or Non-functional Ambulation"35, as follows: community walking (i.e. able to walk outdoors and in the community with or without a walking aid); home/ school walking (i.e. able to walk indoors or inside the classroom with or without a walking aid, but requiring wheelchair assistance or support from others for walking outdoors or in the community); non-functional or non therapeutic walking (i.e. able to take some steps on level ground with or without a walking aid, but requiring supervision).

\section{Data analysis}

Descriptive statistics (means, standard deviations, and frequencies) were used to describe each variable. All analyses were performed with the Statistical Package for Social Sciences (SPSS), version 15.0, SPSS Inc..

\section{Results $: \because$.}

\section{Sociodemographic characteristics}

The sample was composed of 22 participants. Caregivers of 17 participants (77.3\%) were requested to answer the questionnaires.

Table 1 shows the sociodemographic characteristics of adults with CP. Participants aged between 18 to 52 years, with a mean age of 28.7 (SD 10.6) years. The sample had a higher percentage of male participants (63.6\%). Regarding the educational level, seven participants $(31.8 \%)$ had no schooling, 10 (45.5\%) were students or had been educated at special schools, two $(9.1 \%)$ had complete or incomplete elementary school level, three (13.6\%) had complete or incomplete high school level. Nineteen participants $(86.4 \%)$ were living with their parents, one $(4.5 \%)$ was living with her sister, one $(4.5 \%)$ was living with his wife and biological children, and one (4.5\%) was living in a long-term care institution. Only one participant (4.5\%) had a job. With regard to the economic status, one participant (4.5\%) was classified as level A2, two (9.1\%) as level B2, seven (31.8\%) as level $\mathrm{C} 1$, eight $(36.4 \%)$ as level C2, two (9.1\%) as level D, and one $(4.5 \%)$ as level E. It was not possible to assess the economic status of the participant who resided in a long-term care institution.

Table 1. Sociodemographic data.

\begin{tabular}{|c|c|c|c|c|c|c|c|c|c|}
\hline Participant & Interviewee & Age (yrs) & Gender & Employment & Schooling & Marital Status & Housing Status & Children & $E L$ \\
\hline 1 & Own & 37 & $M$ & No & $\mathrm{CHS}$ & Single & Parents & No & $\mathrm{C} 2$ \\
\hline 2 & Caregiver & 52 & $\mathrm{~F}$ & No & NS & Single & Institution & No & * \\
\hline 3 & Caregiver & 20 & $M$ & No & NS & Single & Parents & No & C1 \\
\hline 4 & Caregiver & 19 & $\mathrm{~F}$ & No & SS1 & Single & Parents & No & C1 \\
\hline 5 & Caregiver & 39 & $M$ & No & SS1 & Single & Parents & No & B2 \\
\hline 6 & Caregiver & 22 & $M$ & No & SS1 & Single & Parents & No & $E$ \\
\hline 7 & Own & 35 & $M$ & No & $\mathrm{CHS}$ & Single & Parents & No & $\mathrm{C} 2$ \\
\hline 8 & Caregiver & 21 & $M$ & No & IES & Single & Parents & No & C1 \\
\hline 9 & Caregiver & 18 & $\mathrm{~F}$ & No & SS1 & Single & Parents & No & $\mathrm{D}$ \\
\hline 10 & Caregiver & 52 & $M$ & No & SS1 & Single & Brother & No & $\mathrm{C} 2$ \\
\hline 11 & Caregiver & 23 & $\mathrm{M}$ & No & SS1 & Single & Parents & No & C1 \\
\hline 12 & Own & 37 & $\mathrm{~F}$ & No & SS2 & Single & Parents & No & B2 \\
\hline 13 & Own & 23 & $\mathrm{~F}$ & No & CES & Single & Parents & No & C1 \\
\hline 14 & Caregiver & 24 & $\mathrm{~F}$ & No & NS & Single & Parents & No & C1 \\
\hline 15 & Caregiver & 29 & $\mathrm{~F}$ & No & NS & Single & Parents & No & $\mathrm{C} 2$ \\
\hline 16 & Caregiver & 18 & $M$ & No & SS1 & Single & Parents & No & $\mathrm{C} 2$ \\
\hline 17 & Caregiver & 24 & $F$ & No & NS & Single & Parents & No & $\mathrm{C} 2$ \\
\hline 18 & Caregiver & 23 & $\mathrm{M}$ & No & SS2 & Single & Parents & No & C1 \\
\hline 19 & Caregiver & 20 & M & No & NS & Single & Parents & No & $\mathrm{C} 2$ \\
\hline 20 & Caregiver & 30 & $M$ & No & NS & Single & Parents & No & $D$ \\
\hline 21 & Caregiver & 21 & $F$ & No & SS2 & Single & Parents & No & A2 \\
\hline 22 & Own & 44 & $M$ & Yes & IHS & Married & Wife/children & Yes & $\mathrm{C} 2$ \\
\hline
\end{tabular}

CP: Cerebral Palsy; M: male; F: female; NS: No Schooling; SS1: Special School (unable to read or write); SS2: Special School (able to read and write); IES: Incomplete Elementary School; CES: Complete Elementary School; IHS: Incomplete High School; CHS: Complete High School; EL: Economic Level; A2 to E: Economic Classification Criterion Brazil. *Participant lives in a philanthropic institution of long permanence. 
Table 2. Classification according to the neuromotor dysfunction, topographic distribution, GMFCS and MACS

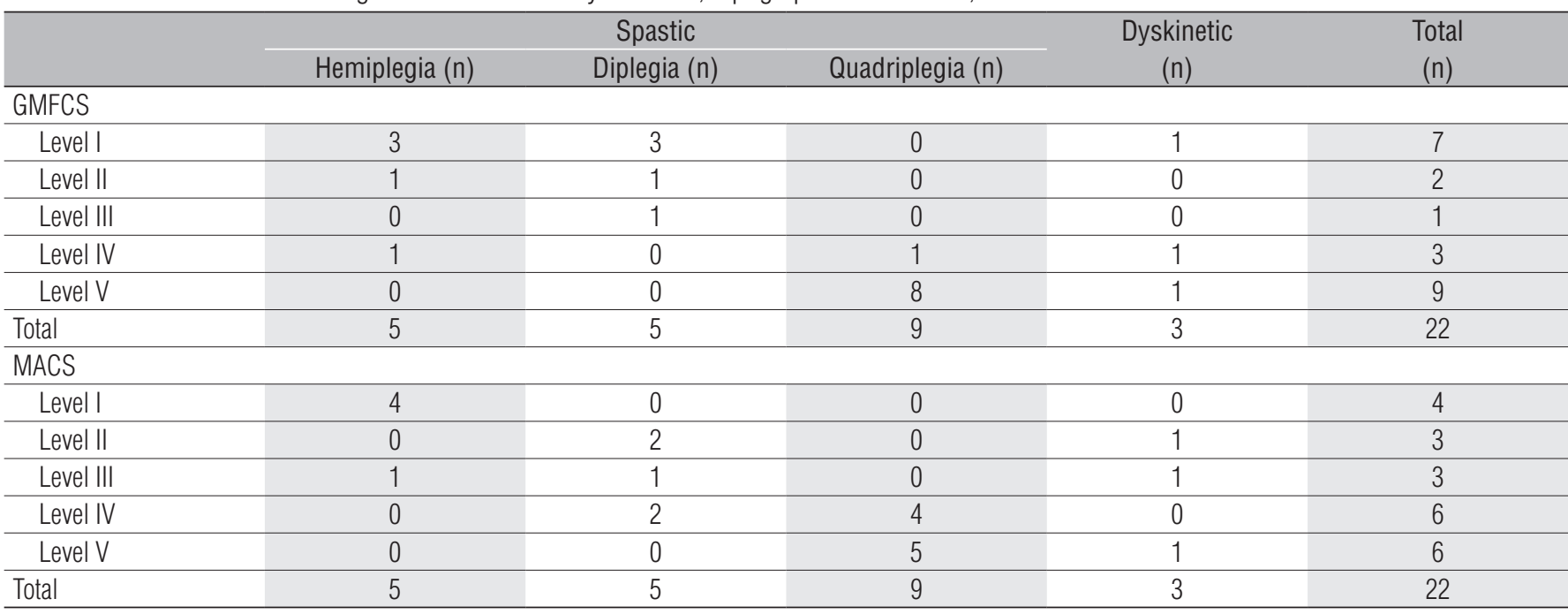

GMFCS: Gross Motor Function Classification System; MACS: Manual Ability Classification System; (n): number of participants.

Table 3. General health, associated conditions and physical complications in adults with CP.

\begin{tabular}{lcc}
\hline $\begin{array}{l}\text { General health, associated conditions } \\
\text { and physical complications }\end{array}$ & $\mathrm{n}$ & $\%$ \\
\hline Epilepsy & 12 & 54.5 \\
\hline Aphasia/dysarthria & 17 & 77.3 \\
\hline Subnormal vision & 4 & 18.2 \\
\hline Swallowing disorders & 9 & 40.9 \\
\hline Bowel and/or bladder dysfunction & 12 & 54.5 \\
\hline Gastroesophageal reflux & 4 & 18.2 \\
\hline Dental problems & 11 & 50 \\
\hline Hip luxation & 2 & 9.1 \\
\hline Pelvic Obliquity & 13 & 59.1 \\
\hline Scoliosis & 20 & 90.9 \\
\hline Fatigue & 9 & 40.9 \\
\hline Osteopenia & 0 & 0.0 \\
\hline Osteoarthritis & 1 & 4.5 \\
\hline Fractures & 2 & 9.1 \\
\hline Contractures & & \\
\hline Absent & 4 & 18.2 \\
\hline Present & 18 & 81.8 \\
\hline Joint Contractures & & \\
\hline Elbow & 4 & 18.2 \\
\hline Grip & 7 & 31.8 \\
\hline Hip & 11 & 50.0 \\
\hline Knee & 15 & 68.2 \\
\hline Ankle & 18 & 81.8 \\
\hline
\end{tabular}

n: number of participants; \%: percentage of participants.

\section{CP Classification}

The classification of neuromotor dysfunction, topographic distribution and function through the GMFCS and MACS are shown in Table 2. Of the 22 participants, $86.4 \%$ had spastic CP and $13.6 \%$ had dyskinetic CP. Other types of CP (e.g. ataxic, hypotonic) were not observed. For practical purposes, patients with mixed CP (spastic and dyskinetic) were classified as dyskinetic CP. Of the participants with spastic CP, $22.7 \%$ were hemiplegic, $22.7 \%$ were diplegic, and $40.9 \%$ were quadriplegic. As for the GMFCS, $45.4 \%$ of participants were classified as level I or II, and $54.5 \%$ as level IV or V, as follows: all participants with spastic quadriplegia and two of the three participants with dyskinetic CP were classified as level IV or V; four of the five hemiplegic participants and four of the five diplegic participants were classified as level I or II. As for the MACS, proportions similar to the GMFCS were observed, with $45.4 \%$ of all participants being classified as level I or II, and $54.5 \%$ as level IV or V. All quadriplegic participants were classified as level IV or V of the MACS, all hemiplegic participants were classified as level I or II, and three of the five diplegic participants and two of the three dyskinetic participants were classified as level I or II.

\section{General health, associated conditions and physical complications}

Information about the general health, associated conditions and physical complications are described in Table 3.

\section{Locomotion}

Of the 22 participants, 12 (54.5\%) did not walk (i.e. 10 never acquired gait and two lost this ability after childhood). Of the 10 participants (45.5\%) who were able to walk, eight (36.4\%) had community walking, one (4.5\%) had walking at home and one (4.5\%) had therapeutic walking. Three participants (13.6\%) who walked used fixed ankle-foot orthoses. Of the participants who were unable to walk, nine (40.9\%) were assisted by another person in a manual wheelchair in 
Table 4. Mode of Locomotion.

\begin{tabular}{|c|c|c|c|c|c|}
\hline & $\begin{array}{c}\text { Hemiplegic } \\
n\end{array}$ & $\begin{array}{c}\text { Diplegic } \\
n\end{array}$ & $\begin{array}{c}\text { Quadriplegic } \\
n\end{array}$ & $\begin{array}{c}\text { Dyskinetic } \\
\mathrm{n}\end{array}$ & $\begin{array}{l}\text { Total } \\
\mathrm{n}(\%) \\
\end{array}$ \\
\hline \multicolumn{6}{|l|}{ Locomotion } \\
\hline Have walked in the past & 0 & 0 & 1 & 1 & $2(9.0)^{*}$ \\
\hline Walk & 4 & 6 & 0 & 0 & $10(45.5)$ \\
\hline Wheelchair & 1 & 0 & 6 & 2 & $9(40.9)$ \\
\hline Crawl & 0 & 0 & 1 & 0 & $1(4.5)$ \\
\hline None & 0 & 0 & 2 & 0 & $2(9.1)$ \\
\hline \multicolumn{6}{|l|}{ Gait Classification } \\
\hline Community & 4 & 4 & 0 & 0 & $8(36.4)$ \\
\hline Home & 0 & 1 & 0 & 0 & $1(4.5)$ \\
\hline Therapeutic & 0 & 1 & 0 & 0 & $1(4.5)$ \\
\hline Ortheses & 1 & 2 & 0 & 0 & $3(13.6)$ \\
\hline
\end{tabular}

n: number of participants, \%: percentage of participants. ${ }^{*}$ Two participants who have walked in the past currently use a wheelchair for locomotion.

and out of house, and one (4.5\%) crawled on the ground. The other two participants $(9.1 \%)$ did not have a wheelchair for locomotion (Table 4).

\section{Discussion $\because \because$.}

The present study characterized a sample of 22 adults with CP living in an inner city of Brazil. Most participants were classified as spastic $\mathrm{CP}$, with a higher proportion of quadriplegics. Although there is a consensus in the literature that the spastic type is the most prevalent $\mathrm{CP}$, the topographic distribution is variable among studies ${ }^{19,36,37}$. According to Andersson and Mattsson $^{19}$, one possible explanation for this fact can be the difference in definitions among researchers, especially when it comes to distinguishing severe diplegic and quadriplegic cases.

In the present study, most hemiplegic and diplegic participants were classified as levels I or II of the GMFCS, and most quadriplegics and dyskinetic were classified as levels IV or V. Although our study is a descriptive report and did not include any inferential analysis, our results appear to be consistent with those of Shevell et al. ${ }^{38}$, who verified a relationship between the GMFCS and the type of CP in 301 children. The authors concluded that there is a correlation between spastic or dyskinetic CP and higher levels of gross motor disability, and between hemiplegia or diplegia and lower levels of gross motor disability ${ }^{38}$.

As for the MACS, quadriplegic and hemiplegic participants showed results similar to those observed for the GMFCS. As for the diplegic and dyskinetic participants, there was a more similar distribution between the levels of minor and major disabilities. These results are consistent with those of studies that have verified the association between the GMFCS and the MACS ${ }^{39,40}$. The MACS is related with the degree of neuromotor compromise of the upper limbs, which is variable among diplegic individuals, as well as with the preservation of cognition, which is very frequent in dyskinetic and diplegic individuals ${ }^{39,40}$.

With regard to sociodemographic characteristics, most participants were male and were classified as belonging to an intermediate economic class. Considering the participants' age group (18-52 years old), it is possible to observe an increased life expectancy, as observed in other countries. Hemming et al. ${ }^{3}$ followed a cohort of individuals with CP born between 1940 and 1960 in the UK. The authors verified that of those individuals who were still alive at 20 years of age, $86 \%$ survived to age 50. According to Hutton and Pharoah ${ }^{4}$, the severity and the number of comorbidities play an important role in the survival of individuals with CP. For example, in a study carried out by those authors, $99 \%$ of individuals with mild CP survived to age 30 , whereas only $33 \%$ of individuals with four serious comorbidities survived to the same age. According to Strauss et al.', since the 1980s a greater importance has been given to the proper nutritional status of children and adults with disabilities, and to the early detection and vigorous treatment of infections, which has been facilitated by the improved technological support in healthcare services.

In Brazil, life expectancy has increased in the general population, given the improved living conditions and healthcare ${ }^{41}$. However, this study showed that the maximum age of participants is still below the expectation of life in Brazil, which is 71.3 years ${ }^{41}$. This is a reality observed in other studies with individuals with $\mathrm{CP}^{2-4,23,42}$. Although life expectancy of individuals with $\mathrm{CP}$ has increased, it is still below that of the general population, even in developed countries ${ }^{2-4,23,42}$.

The participants in this study showed restrictions in social participation, except for one participant, who was able to obtain employment, form his own family, and be independent from his parents. Furthermore, participants showed lower levels of education. This reality is different from that of developed countries; nevertheless, even in developed countries, 
social participation of adults with CP is still lower than that observed in the general population ${ }^{19,20}$. In a study carried out in Denmark ${ }^{20}$, from 486 adults with CP who were born between 1965 and 1970, 68\% lived independently, 28\% formed their own family, $19 \%$ had children, and $45 \%$ had a job ${ }^{22}$. In another study in Sweden ${ }^{19}$, from 221 adults with CP, $61 \%$ lived independently, $24 \%$ worked full-time, $57 \%$ completed two or three years of education after the age of 16 years, and $14 \%$ formed their own family. According to the authors of these studies ${ }^{19,20}$, the restrictions in social participation of adults with $\mathrm{CP}$ are associated to the severity of their disability, type of neuromotor and topographical classification, degree of functional dependence, absence of gait, and to associated conditions such as epilepsy and cognitive impairment. In the present study, the patient who showed better social participation had incomplete high school, was diplegic with a GMFCS level I and MACS level II, and showed community walking. This participant was capable of independently answering the questionnaire and reported not to have epilepsy.

It is possible that the important restrictions in social participation and the lower educational level of the study participants may be related to their associated conditions, since $54 \%$ of them reported epilepsy, and $77.3 \%$ reported communication disorders. Furthermore, $77.3 \%$ of participants needed assistance to answer the questionnaire due to cognitive impairment or communication disorders. However, it is also necessary to consider the possible influence of environmental factors ${ }^{23,32}$. Although Brazil has shown economic and social progresses in recent years, such as the decrease in poverty and the increase in the Human Development Index (HDI) ${ }^{41}$, the reality of the social, cultural and economic environments as well as the process of social inclusion are still very different from the situation observed in developed countries.

Participants or caregivers were asked about the existence of health problems and associated conditions. The main disturbances reported were related to communication, such as aphasia/dysarthria, epilepsy, bowel and/or bladder dysfunction, swallowing disorders and dental problems. These results are in conformity with others from previous studies ${ }^{16,23,31,32,36,42}$, although gastroesophageal reflux, hearing and visual deficits are also frequently reported in the literature ${ }^{16,23,31,36,42}$. According to Turk $^{42}$, most of the health problems or associated conditions of adults with $\mathrm{CP}$ are the same ones that accompany childhood. However, adults with CP complain more of dental, urinary and intestinal problems, pain, and especially of disorders of the musculoskeletal system ${ }^{36,42}$.

A large number of participants with scoliosis, pelvic obliquity and muscle contractures was observed in this study. Only two participants reported fractures due to falls during childhood. No participant reported osteoporosis, one reported osteoarthritis, and two reported hip luxation. However, such findings should be interpreted with caution, since the participants did not have exams to confirm these diagnoses, and also showed little knowledge about the concepts and the evolution of CP.

In a descriptive study of 72 adults with $\mathrm{CP}$ in Italy, Bottos et al. ${ }^{16}$ observed scoliosis above $30^{\circ}$ in $20.3 \%$ of the participants, and hip luxation or subluxation in $28.2 \%$ of them. In a study with 63 adult women with CP, Turk et al..$^{36}$ observed hip deformities (pelvic obliquity or hip luxation) in $40 \%$ of the participants, spinal deformities (scoliosis or kyphosis) in 53\%, and muscle contractures in $75 \%$ of them. According to the literature ${ }^{6,7,16,19,43}$, deformities such as scoliosis, pelvic obliquity and hip luxation are more common in severely affected adults, typically those with quadriplegic CP or those unable to walk. On the other hand, muscle contractures, feet deformity and osteoarthritis are observed in all types of CP. In this study, there was a large proportion of individuals with contractures (81.8\%), with these being more common in the ankle extensors, followed by the knee, hip, wrist and elbow flexors. Two hemiplegic, one diplegic and one dyskinetic participant had no contractures, whereas all quadriplegics had two to five muscle groups affected by contractures. Contractures were observed in all participants who did not walk and in $60 \%$ of those who walked. These results are similar to those reported by Andersson and Mattsson ${ }^{19}$ in a previous study with adults with CP. The authors identified contractures in $80 \%$ of the sample: of the 27 quadriplegic, 25 couldn't walk and, between then, only one reported not having contracture; of the 47 hemiplegics who could walk, 31 reported contractures ${ }^{19}$. Ultrasound studies investigating muscular changes in individuals with $\mathrm{CP}^{8,9}$ show that tissue adaptations that occur in this population are similar to those following immobilization and disuse, or those due to excessive use or unfavorable biomechanical load. Contractures, muscle atrophy and changes in muscle architecture are consequences of these adaptations, reflecting the dynamic nature of the muscular system ${ }^{19,44}$.

Fatigue is described as the decreased ability to maintain muscle strength and to perform tasks; it is the experience of feeling exhausted, tired, weak or lacking energy ${ }^{13}$. In this study, fatigue was reported by nine participants (40.9\%), most of whom were able to walk. According to Jahnsen et al. ${ }^{13}$, fatigue requires a certain amount of activity; thus, individuals with severe motor disabilities may not have sufficient motor skills to become physically fatigued.

Walking was observed in 10 participants (45.5\%), including four hemiplegic and six diplegic individuals. Most of these individuals had community walking. Twelve quadriplegic participants did not walk. According to literature ${ }^{17,45,46}$, although the analysis on the prognosis for ambulation in individuals with 
$\mathrm{CP}$ is complex and multifactorial, the topographic diagnosis of $\mathrm{CP}$ is an important prognostic factor; that is, hemiplegic, followed by diplegic individuals, generally have a more favorable prognosis for the development of gait, while the prognosis is less favorable for quadriplegic individuals ${ }^{17,45,46}$.

One dyskinetic participant had lost gait at the age of 32 years due to spondylolisthesis followed by myelopathy. According to Murphy ${ }^{43}$, it is possible that spondylolisthesis occur in adults with dyskinetic CP due to contort dystonic postures of the head and neck. Another spastic quadriplegic participant had lost gait at the age of 12 years due to deterioration of functional capacity. Results of previous studies have shown that a progressive functional impairment can occur early in individuals with CP, with some of them losing their walking ability between 25 and 35 years of age $\mathrm{e}^{14,17,19,23,42}$. According to Bott and Gericke $^{17}$, among the several factors related to the loss of gait in adults with $\mathrm{CP}$, the principal one would be the degenerative processes and joint pain resulting from the use of unfavorable biomechanics, imbalance between the demand for walking in a dynamic environmental context, and from the onset of fatigue and orthopedic surgeries that do not take into account the functional and compensatory responses of the individual.

Recently, a longitudinal study ${ }^{14}$ showed that in 146 adults with $\mathrm{CP}, 52 \%$ reported functional limitation in walking. This limitation was mainly associated with bilateral CP type (quadriplegic and diplegic) and GMFCS level III, and it was correlated with pain complaints, fatigue and loss of body balance. The authors concluded that individuals with bilateral CP and GMFCS level III overload their musculoskeletal systems in order to meet their functional and social goals. Moreover, other environmental factors, such as the provision of rehabilitation, physical training for adults with $\mathrm{CP}$ and environmental adaptations are crucial for walking ability.

Several studies ${ }^{16,17,19,23,42}$ cautioned that, in general, there is a discontinuity in the rehabilitation of individuals with $\mathrm{CP}$ in adulthood. When offered, these therapies are directed to the needs of children. Thorpe ${ }^{47}$ points out that there are only a few studies on rehabilitation or physical activity in adults with $\mathrm{CP}$, and given the increase in their life expectancy, it is imperative that the scientific community promotes grounding for appropriate therapeutics to their needs.

\section{Study limitations}

It is important to note that this study relied on a convenience sample, thus there are limitations in generalizing the results. However, the present findings are important for stimulating discussion about life expectancy, disability, limitations and needs for assistance for Brazilian adults with CP. Future studies should include information not collected in this study, such as cognitive assessment, history of surgeries and neurolysis, and more information about language disorders.

\section{Conclusions $\because \therefore$.}

In accordance to previous studies, the present study indicated that adults with CP have specific characteristics and needs. Participants in the study showed important social restrictions, and had major musculoskeletal deficiencies and progressive limitations in gait. Besides, the participants and caregivers demonstrated little knowledge on $\mathrm{CP}$ and its evolution.

Considering the increasing life expectancy of these individuals, public policies aiming at better and greater access to information, medical services, education, work opportunities, and adaptations to physical environments that provide greater accessibility to public spaces are needed. It is important to emphasize the need for the development of specific physical training programs targeting the deficiency and limitations observed in individuals with $\mathrm{CP}$ in the adulthood.

\section{References : :}

1. Rosenbaum P, Paneth N, Leviton A, Goldstein M, Bax M, Damiano D, et al. A report: the definition and classification of cerebral palsy April 2006. Dev Med Child Neurol Suppl. 2007;49(109):8-14.

2. Strauss D, Brooks J, Rosenbloom L, Shavelle R. Life expectancy in cerebral palsy: an update. Dev Med Child Neurol. 2008;50(7):487-93

3. Hemming K, Hutton JL, Pharoah PO. Long-term survival for a cohort of adults with cerebral palsy. Dev Med Child Neurol. 2006;48(2):90-5.

4. Hutton JL, Pharoah PO. Life expectancy in severe cerebral palsy. Arch Dis Child. 2006;91(3):254-8

5. Donkervoort M, Roebroeck M, Wiegerink D, van der Heijden-Maessen H, Stam H; Transition Research Group South West Netherlands. Determinants of functioning of adolescents and young adults with cerebral palsy. Disabil Rehabil. 2007;29(6):453-63.
6. Paterson M. Progression and correction of deformities in adults with cerebral palsy. Adv Clin Neurosci Rehabil. 2004:4(3):27-31.

7. Horstmann HM, Hosalkar H, Keenan MA. Orthopaedic issues in the musculoskeletal care of adults with cerebral palsy. Dev Med Child Neurol. 2009;51 Suppl 4:S99-105.

8. Ohata K, Tsuboyama T, Ichihashi N, Minami S. Measurement of muscle thickness as quantitative muscle evaluation for adults with severe cerebral palsy. Phys Ther. 2006;86(9):1231-9.

9. Moreau NG, Teefey SA, Damiano DL. In vivo muscle architecture and size of the rectus femoris and vastus lateralis in children and adolescents with cerebral palsy. Dev Med Child Neurol. 2009;51(10):800-6.

10. Carter DR, Tse B. The pathogenesis of osteoarthritis in cerebral palsy. Dev Med Child Neurol 2009;51 Suppl 4:S79-83. 
11. Henderson RC, Kairalla J, Abbas A, Stevenson RD. Predicting low bone density in children and young adults with quadriplegic cerebral palsy. Dev Med Child Neurol. 2004;46(6):416-9.

12. Sheridan KJ. Osteoporosis in adults with cerebral palsy. Dev Med Child Neurol. 2009;51 Suppl 4:38-51.

13. Jahnsen R, Villien L, Stanghelle JK, Holm I. Fatigue in adults with cerebral palsy in Norway compared with the general population. Dev Med Child Neurol. 2003;45(5):296-303.

14. Opheim A, Jahnsen R, Olsson E, Stanghelle JK. Walking function, pain, and fatigue in adults with cerebral palsy: a 7-year follow-up study. Dev Med Child Neurol. 2009;51(5):381-8.

15. Vogtle LK. Pain in adults with cerebral palsy: impact and solutions. Dev Med Child Neurol. 2009;51 Suppl 4:113-21.

16. Bottos M, Feliciangeli A, Sciuto L, Gericke C, Vianello A. Functional status of adults with cerebral palsy and implications for treatment of children. Dev Med Child Neurol. 2001;43(8):516-28.

17. Bottos M, Gericke C. Ambulatory capacity in cerebral palsy: prognostic criteria and consequences for intervention. Dev Med Child Neurol. 2003:45(11):786-90.

18. Tosi LL, Maher N, Moore DW, Goldstein M, Aisen ML. Adults with cerebral palsy: a workshop to define the challenges of treating and preventing secondary musculoskeletal and neuromuscular complications in this rapidly growing population. Dev Med Child Neurol. 2009;51 Suppl 4:2-11.

19. Andersson C, Mattsson E. Adults with cerebral palsy: a survey describing problems, needs, and resources, with special emphasis on locomotion. Dev Med Child Neurol. 2001;43(2):76-82.

20. Michelsen SI, Uldall P, Hansen T, Madsen M. Social integration of adults with cerebral palsy. Dev Med Child Neurol. 2006;48(8):643-9

21. Mezaal AM, Nouri KA, Abdool S, Safar K, Nadeem AS. Cerebral palsy in adults consequences of non progressive pathology. Open Neurol J. 2009;3:24-6.

22. Ando N, Ueda S. Functional deterioration in adults with cerebral palsy. Clin Rehabil. 2000;14(3):300-6

23. Haak P, Lenski M, Hidecker MJ, Li M, Paneth N. Cerebral palsy and aging. Dev Med Child Neurol. 2009;51 Suppl 4:16-23.

24. ABEP - Associação Brasileira de Empresas de Pesquisa. Critério de classificação econômica Brasil [homepage na Internet]. São Paulo: ABEP; [atualizada em 2005; acesso em 03 Mar 2009]. Disponível em: http://www.abep.org/novo/Content.aspx?ContentID=302

25. Palisano R, Rosenbaum P, Walter S, Russell D, Wood E, Galuppi B. Development and reliability of a system to classify gross motor function in children with cerebral palsy. Dev Med Child Neurol. 1997;39(4):214-23.

26. Palisano R, Rosenbaum P, Bartlett D, Livingston M. Gross motor function classification system: expanded and revised. Can Child Centre for Childhood Disability Research, McMaster University [periódico na Internet]. 2007 [ acesso em 10 Mar 2009]; [aproximadamente 4p.]. Disponível em: http://motorgrowth.canchild.ca/en/GMFCS/resources/GMFCS-ER.pdf

27. Sandstrom K, Alinder J, Oberg B. Descriptions of functioning and health and relations to a gross motor classification in adults with cerebral palsy. Disabil Rehabil. 2004;26(17):1023-31.

28. McCormick A, Brien M, Plourde J, Wood E, Rosenbaum P, McLean J. Stability of the gross motor function classification system in adults with cerebral palsy. Dev Med Child Neurol. 2007;49(4):265-9.
29. Donnelly C, Parkes J, McDowell B, Duffy C. Lifestyle limitations of children and young people with severe cerebral palsy: a population study protocol. J Adv Nurs. 2007;61(5):557-69.

30. Eliasson AC, Krumlinde-Sundholm L, Rosblad B, Beckung E, Arner M, Öhrvalll AM, et al. The manual ability classification system (MACS) for children with cerebral palsy: scale development and evidence of validity and reliability. Dev Med Child Neurol. 2006;48(7):549-54.

31. Rapp CE, Torres MM. The adult with cerebral palsy. Arch Fam Med. 2000;9:466-72.

32. Liptak GS. Health and well being of adults with cerebral palsy. Curr Opin Neurol. 2008;21(2):136-42.

33. Tardieu C, Lespargot A, Tabary C, Bret MD. For how long must the soleus muscle be stretched each day to prevent contracture? Dev Med Child Neurol. 1988;30(1):3-10.

34. Harvey LA, Batty J, Crosbie J, Poulter S, Herbert RD. A randomized trial assessing the effects of 4 weeks of daily stretching on ankle mobility in patients with spinal cord injuries. Arch Phys Med Rehabil. 2000;81(10):1340-7.

35. Montgomery PC. Predicting potential for ambulation in children with cerebral palsy. Pediatr Phys Ther. 1990;10:148-55.

36. Turk MA, Geremski CA, Rosenbaum PF, Weber RJ. The health status of women with cerebra palsy. Arch Phys Med Rehabil. 1997;78(12 Suppl 5):S10-7.

37. Murphy KP, Molnar GE, Lankasky K. Medical and functional status of adults with cerebral palsy. Dev Med Child Neurol. 1995;37(12):1075-84.

38. Shevell MI, Dagenais L, Hall N; Repacq Consortium. The relationship of cerebral palsy subtype and functional motor impairment: a population-based study. Dev Med Child Neurol. 2009;51(11):872-7.

39. Gunel MK, Mutlu A, Tarsuslu T, Livanelioglu A. Relationship among the manual ability classification system (MACS), the gross motor function classification system (GMFCS), and the functional status (WeeFIM) in children with spastic cerebral palsy. Eur J Pediatr. 2008;168(4):477-85.

40. Carnahan KD, Arner M, Hägglund G. Association between gross motor function (GMFCS) and manual ability (MACS) in children with cerebral palsy. A population-based study of 359 children. BMC Musculoskelet Disord. 2007;8(50):3-7.

41. Guimarães $A Q$, Wanderley $B C$. Projeto avaliação de Minas Gerais nos primeiros anos do século XXI - relatório das áreas econômica e social - segundo semestre de 2006. Belo Horizonte: Fundação João Pinheiro; 2006.

42. Turk MA. Health, mortality, and wellness issues in adults with cerebral palsy. Dev Med Child Neurol. 2009;51 Suppl 4:S24-9.

43. Murphy KP. Cerebral palsy lifetime care - four musculoskeletal conditions. Dev Med Child Neurol. 2009;51 Suppl 4:S30-7.

44. Gough M. Muscle deformity in cerebral palsy: reduced use, overuse, or both? Dev Med Child Neurol. 2009;51(10):765-9.

45. Sala DA, Grant AD. Prognoses for ambulation in cerebral palsy. Dev Med Child Neurol. 1995;37(11):1020-6

46. Beckung E, Hagberg G, Uldall P, Cans C; Surveillance of Cerebral Palsy in Europe. Probability of walking in children with cerebral palsy in Europe. Pediatrics. 2008;121(1):e187-92.

47. Thorpe D. The role of fitness in health and disease: status of adults with cerebral palsy. Dev Med Child Neurol. 2009:51 Suppl 4:S52-8. 
Appendix 1. Characterization of Adults with Cerebral Palsy Residents of Diamantina- MG, Brazil.

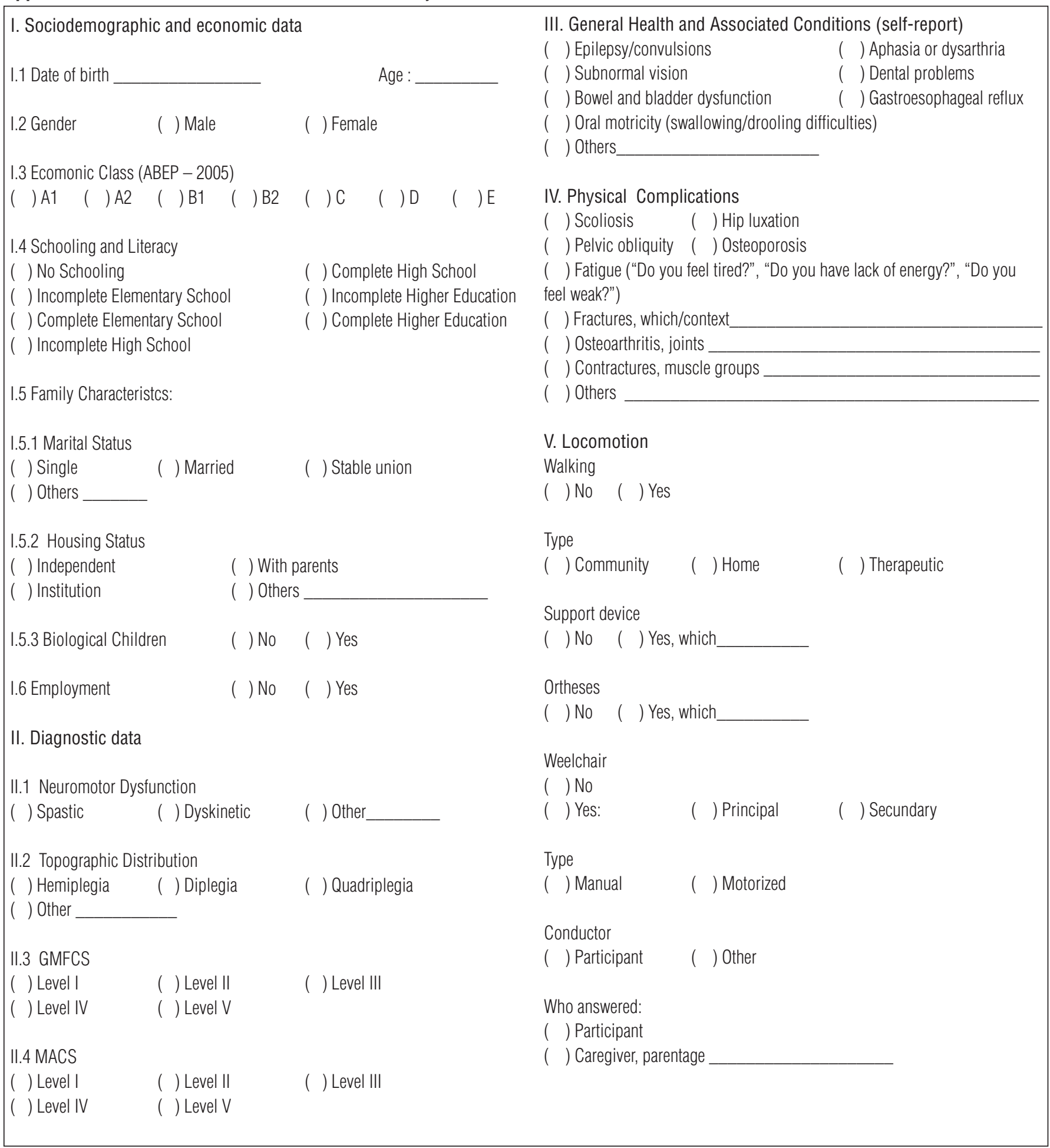

